\title{
VEGETASI DI KAWASAN SEMPADAN EMBUNG BUAL,DESA AIK BUAL KECAMATAN KOPANG KABUPATEN LOMBOK TENGAH
}

\author{
The Vegetation in the Border Area of Bual Retention Basin, Aik Bual Village Kopang Sub \\ District Lombok Tengah Regency
}

\author{
Diah Permata Sari ${ }^{\star}$, Kornelia Webliana B dan Maiser Syaputra \\ Jurusan Kehutanan, Fakultas Pertanian, Universitas Mataram \\ Jalan Pendidikan No. 37 Mataram \\ `Email :diahpermatasari@unram.ac.id
}

\begin{abstract}
Embung Bual is one of the tourist attraction objects in Lombok Tengah Regency. Vegetation analysis in the border area of Embung Bual is necessary to know and to identify the structure and composition of vegetation in the border area of Embung Bual because vegetation is an important elemen in water conservation efforts. This study aims to analyze the structure and composition by analyzing the importance value index and diversity index in the border area of Embung Bual. Vegetation in the border area of Embung Bual was analyzed by using the striped path method with nested quadrats. The vegetation data obtained were carried out with an importance value index (INP) and diversity index. The results showed that the Embung Bual border area was dominated by Mahagony species at the tree life phase with an INP value of $60.21 \%$, the pole life phase was dominated by Cempaka species with an INP value of $74.36 \%$, at the sapling phase was dominated by Kumbi with INP value 55,09\% and the seedling life phase was dominated by Mahagony species with an INP value of 88.54\%. Embung Bual border area has a composition of 22 species and has a Simpson diversity index with a value of 0.86 which is included in the high category, and has a Shannon diversity index with a value of 2.43 which is included in the high category.
\end{abstract}

Keywords : Vegetation Analysis, Embung Bual, Border Area

\section{ABSTRAK}

Embung Bual merupakan salah satu objek daya tarik wisata di Kabupaten Lombok Tengah. Analisis vegetasi di kawasan sempadan Embung Bual sangat diperlukan untuk mengetahui dan mengidentifikasi struktur dan komposisi vegetasi pada kawasan sempadan Embung Bual. Hal ini karena vegetasi merupakan unsur penting dalam upaya konservasi air. Penelitian ini bertujuan untuk menganalisis struktur dan komposisi vegetasi berupa indeks nilai penting dan indeks keanekaragaman pada kawasan sempadan Embung Bual. Vegetasi ini dianalisis dengan menggunakan metode jalur berpetak dengan petak kuadrat ganda (nested quadrat). Data vegetasi yang diperoleh dilakukan analisis indeks nilai penting (INP) dan indeks keanekaragaman. Hasil penelitian menunjukkan kawasan sempadan Embung Bual didominasi oleh jenis Mahoni pada tingkat hidup pohon dengan nilai INP $60,21 \%$, pada tingkat hidup tiang didominasi oleh jenis Cempaka dengan nilai INP $74,36 \%$, pada tingkat sapihan didominasi oleh jenis Kumbi dengan nilai INP 55,09\% serta pada tingkat hidup semai didominasi oleh jenis Mahoni dengan nilai INP 88,54\%. Kawasan sempadan Embung Bual memiliki komposisi 22 spesies dan memiliki indeks keanekaragaman Simpson dengan nilai 0,86 yang termasuk ke dalam kategori tinggi, serta 
Jurnal Belantara Vol. 2, No. 2, Agustus 2019 (119-126)

memiliki indeks keanekaragaman Shannon dengan nilai 2,43 yang termasuk ke dalam kategori tinggi.

Kata Kunci : Analisis Vegetasi, Embung Bual, Kawasan Sempadan

\section{PENDAHULUAN}

Air merupakan sumber kehidupan penting yang sangat bermanfaat dalam pemenuhan segala kebutuhan manusia dan makhluk hidup lainnya. Salah satu sumber air tawar yang dapat dimanfaatkan makhluk hidup berasal dari mata air. Keberadaan sumber-sumber mata air harus dilestarikan karena akan berpengaruh pada kelestarian kuantitas maupun kualitasnya. Kuantitas air bervariasi berdasarkan waktu, ruang dan kondisi tata guna lahan daerah tangkapan airnya.

Pengelolaan vegetasi di daerah tangkapan air dapat memengaruhi waktu dan penyebaran aliran (Asdak, 2010). Kegiatan tata guna lahan yang dapat merubah kondisi alami vegetasi dapat juga berpengaruh terhadap hasil air. Vegetasi merupakan unsur penting untuk usaha konservasi air (Azizah, 2017). Peran vegetasi tersebut ditentukan oleh struktur dan komposisinya (Basrowi, Hendra, \& Hariani, 2018). Perubahan dan pengurangan struktur dan komposisi vegetasi dapat menyebabkan degradasi sifat fisik tanah dan akan mengurangi kemampuan tanah dalam menyimpan air (Yulistyarini, 2011).

Menurut Keputusan Presiden No. 32 Tahun 1990 tentang Pengelolaan Kawasan Lindung, kawasan sekitar mata air merupakan salah satu kawasan lindung yang berfungsi untuk mempertahankan kelestarian fungsi mata air. Vegetasi pada kawasan sempadan mata air berperan sebagai daerah resapan air, pengendali erosi, dan menjaga kelestarian kuantitas maupun kualitas air. Oleh sebab itu, pengelolaan dan pelestarian vegetasi di kawasan sempadan diperlukan untuk mengembalikan fungsi kawasan sempadan serta meningkatkan kualitas air (Agustina \& Arisoesilaningsih, 2013).

Embung Bual merupakan salah satu objek daya tarik wisata di Kabupaten Lombok Tengah. Kawasan ini terdiri dari daerah dekat dengan sumber mata air seluas $1 \mathrm{Ha}$ yang digunakan oleh masyarakat sebagai sumber air minum, mencuci, mandi dan mengairi tanaman. Selain itu, terdapat daerah sempadan di sekitar mata air seluas $3 \mathrm{Ha}$ yang ditanami berbagai jenis pohon oleh masyarakat untuk menjaga kelestarian kawasan tersebut.

Analisis vegetasi di kawasan sempadan mata air Embung Bual sangat diperlukan untuk mengetahui struktur dan komposisi vegetasi pada kawasan sempadan mata air Embung Bual. Hal ini dilakukan karena vegetasi di kawasan sempadan mata air merupakan unsur penting dalam upaya konservasi air. Oleh sebab itu, analisis vegetasi pada kawasan sempadan mata air Embung Bual perlu dilakukan sebagai langkah awal mendukung upaya konservasi air secara ekologis. Selain itu, hasil penelitian ini diharapkan sebagai data dasar untuk referensi dan pertimbangan dalam pengelolaan kawasan sempadan Embung Bual terkait dengan kegiatan penghijauan kawasan sempadan tersebut.

\section{METODE}

Vegetasi di kawasan sempadan Embung Bual dianalisis dengan menggunakan metode jalur berpetak. Jalur berpetak dibuat dengan petak kuadrat ganda (nested quadrat) dengan ukuran petak ukur kuadrat untuk semai $2 \mathrm{~m} \times 2 \mathrm{~m}$, untuk sapihan $5 \mathrm{~m} \times 5 \mathrm{~m}$, untuk tiang $10 \mathrm{~m} \times 10 \mathrm{~m}$, dan pohon $20 \mathrm{~m} \times 20 \mathrm{~m}$ (Kusmana, 1997 dalam Indriyanto, 2006). Jarak petak ukur kuadrat ganda paling dekat dengan tepi embung sejauh 5 meter dan 50 meter jarak antar petak ukur kuadrat. Desain pengambilan data vegetasi dengan metode jalur berpetak ditunjukkan dalam Gambar 1 sebagai berikut. 


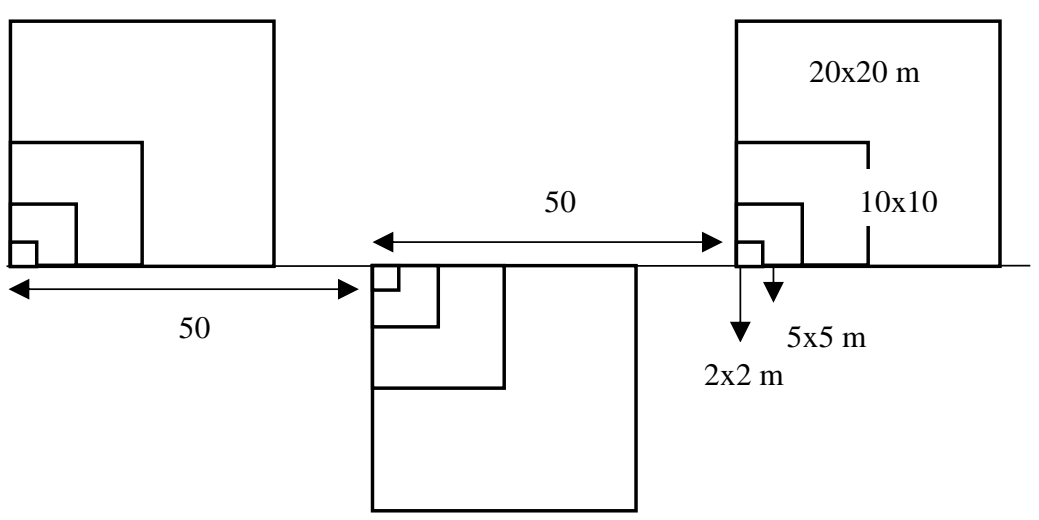

Gambar 1. Desain Pengambilan Data Vegetasi

Figure 1. The Design of Vegetation Data Collection

Data vegetasi yang diperoleh digunakan untuk analisis Indeks Nilai Penting (INP) dan indeks keanekaragaman pada kawasan sempadan Embung Aik Bual. Indeks nilai penting (INP) dianalisis pada setiap tingkatan pertumbuhan pohon, sedangkan indeks keanekaragaman dianalisis untuk seluruh spesies/jenis pada masing-masing petak ukur. Indeks nilai penting (INP) merupakan parameter kuantitatif yang dapat menunjukkan spesies dominan dalam dalam suatu tegakan hutan atau komunitas tumbuhan (Soegianto, 2004 dalam Indriyanto 2006). Indeks nilai penting (INP) merupakan hasil penjumlahan dari nilai kerapatan relatif, dominansi relatif dan frekuensi relatif. Analisis INP dilakukan dengan langkah-langkah sebagai berikut;

$$
\begin{aligned}
& \text { kerapatan jenis } A=\frac{\text { jumlah seluruh spesies dalam seluruh petak ukur }}{\text { luas seluruh petak contoh dalam ha }} \\
& \text { kerapatan relatif }(K R) \text { jenis } A=\frac{\text { kerapatan jenis } A}{\text { jumlah kerapatan jenis }} \times 100 \% \\
& \text { dominansi }(D) \text { jenis } A=\frac{\text { luas bidang dasar jenis } A}{\text { luas seluruh petak contoh dalam ha }} \\
& \text { dominansi relatif }(D R) \text { jenis } A=\frac{\text { dominansi jenis } A}{\text { jumlah dominansi jenis }} \times 100 \% \\
& \text { frekuensi }(F) \text { jenis } A=\frac{\text { jumlah petak ukur yang dijumpai jenis } A}{\text { jumlah seluruh petak ukur }} \\
& \text { frekuensi relatif }(F R) \text { jenis } A=\frac{\text { frekuensi jenis } A}{\text { jumlah frekuensi jenis }} \times 100 \% \\
& \text { INP jenis } A=K R \text { jenis } A+D R \text { jenis } A+F R \text { jenis } A
\end{aligned}
$$

Indeks keanekaragaman dapat digunakan untuk menunjukkan tingkat diversitas atau keanekaragaman spesies atau jenis penyusun satu atau beberapa tegakan hutan atau komunitas tumbuhan. Selain itu, indeks keanekaragaman spesies dapat juga digunakan untuk mengukur stabilitas komunitas (Soegianto, 1994 dalam Indriyanto 2006). Indeks keanekaragaman yang digunakan yaitu indeks Simpson dan indeks Shannon. Indeks diversitas Simpson berkisar antara 0 sampai 1, semakin mendekati angka 1 maka indeks diversitasnya tinggi dan semakin mendekati nol maka berarti semakin rendah. Indeks keanekaragaman/diversitas (ID) Simpson dihitung dengan rumus : 


$$
\lambda=\frac{\sum n(n-1)}{N(N-1)} I D \text { Simpson }=1-\lambda
$$

Indeks diversitas Shannon memiliki kriteria rendah apabila nilainya kurang dari 1,5; sedang apabila memiliki nilai 1,5 sampai 2 dan tinggi apabila memiliki nilai lebih dari 2 . Indeks keanekaragaman/diversitas (ID) Shannon dihitung dengan rumus :

$$
H^{\prime}=-\sum\left[\left(\frac{n}{N}\right) \ln \left(\frac{n}{N}\right)\right]
$$

\author{
Keterangan : \\ $\mathrm{n}=$ jumlah individu spesies ke $i$ \\ $\mathrm{N}=$ jumlah seluruh individu seluruh spesies \\ $\mathrm{H}^{\prime}$ = indeks Shannon
}

\title{
HASIL dan PEMBAHASAN
}

Indeks nilai penting (INP) merupakan parameter kuantitatif dalam analisis vegetasi yang menunjukkan spesies dominan dalam suatu kawasan atau komunitas tumbuhan. Data vegetasi dalam suatu komunitas tumbuhan ditunjukkan dari jenis penyusun, jumlah jenis, jumlah individu setiap jenis, luas bidang dasar, tinggi dan atribut lainnya. Berdasarkan datadata tersebut dilakukan analisis vegetasi untuk menunjukkan struktur dan komposisinya dari nilai kerapatan, dominansi, dan frekuensi. Kerapatan menunjukkan jumlah individu setiap jenis pada setiap luas wilayah. Selain itu, dominansi menunjukkan tingkat penutupan wilayah dari luas bidang dasar setiap individu atau dari luas penutupan tajuknya. Frekuensi menunjukkan seberapa sering jenis-jenis tertentu muncul dalam keseluruhan petak ukur dalam keseluruhan luas wilayah. Jadi, indeks nilai penting (INP) merupakan penjumlahan dari nilai kerapatan relatif $(K R)$, dominansi relatif $(D R)$ dan frekuensi relatif $(F R)$.

Indeks nilai penting (INP) dibedakan ke dalam seluruh tingkat hidup pohon yaitu semai, sapihan, tiang dan pohon. Hasil penelitian menunjukkan bahwa pada tingkat hidup pohon, jenis yang ditemukan ada 14 jenis. Berdasarkan hasil analisis vegetasi yang ditunjukkan pada Tabel 1, nilai kerapatan relatif, frekuensi relatif dan dominansi relatif yang paling tinggi yaitu jenis Mahoni.Oleh sebab itu, nilai INP yang paling tinggi yaitu jenis Mahoni yaitu $60,21 \%$ yang merupakan jenis pohon yang dominan pada kawasan sempadan Embung Bual. Selanjutnya, jenis yang dominan setelah Mahoni yaitu Cempaka $(45,51 \%)$ dan Nangka (37,03\%), sedangkanjenis yang paling tidak dominan yaitu Pulai $(5,45 \%)$ dan Kumbi (5,83\%).

Tabel 1. Indeks Nilai Penting Pohon

Table 1. The Importance Value of Trees

\begin{tabular}{lllcccc}
\hline No & \multicolumn{1}{c}{ Jenis Pohon } & \multicolumn{1}{c}{ Nama IImiah } & $\begin{array}{c}\text { Kerapatan } \\
\text { Relatif (KR) } \\
(\%)\end{array}$ & $\begin{array}{c}\text { Frekuensi } \\
\text { Relatif (FR) } \\
(\%)\end{array}$ & $\begin{array}{c}\text { Dominansi } \\
\text { Relatif } \\
\text { (DR)(\%) }\end{array}$ & INP (\%) \\
\hline 1 & Nyamplung & Calophyllum inophyllum & 1,79 & 3,03 & 3,91 & 8,73 \\
2 & Coklat & Theobroma cacao & 3,57 & 6,06 & 0,76 & 10,39 \\
3 & Nangka & Artocapus heterophyllus & 16,07 & 12,12 & 8,84 & 37,03 \\
4 & Mahoni & Swietenia mahagoni & 23,21 & 15,15 & 21,84 & 60,21 \\
5 & Bunai & Antidesma bunius & 3,57 & 6,06 & 1,52 & 11,15 \\
6 & Ara & Picus sp & 5,36 & 6,06 & 8,46 & 19,88 \\
7 & Cempaka & Magmolia champaca & 17,86 & 15,15 & 12,50 & 45,51 \\
8 & Awar-awar/Lembokek & Picus septica & 5,36 & 6,06 & 2,53 & 13,94 \\
9 & Kumbi/Jembirit & Tabernaemontana sphaerocarpa & 1,79 & 3,03 & 1,01 & 5,83 \\
10 & Kepundeng & Baccaurea racemosa & 5,36 & 9,09 & 15,66 & 30,10
\end{tabular}


Jurnal Belantara Vol. 2, No. 2, Agustus 2019 (119-126)

\begin{tabular}{lllcccc}
\hline 11 & Pulai & Alstonia scholaris & 1,79 & 3,03 & 0,63 & 5,45 \\
12 & Sonokeling & Dalbergia latifolia & 10,71 & 9,09 & 5,56 & 25,36 \\
13 & Sengon & Albizia chinensis & 1,79 & 3,03 & 14,52 & 19,34 \\
14 & Terep & Picus elastica & 1,79 & 3,03 & 2,27 & 7,09 \\
& & Jumlah & 100 & 100 & 100 & 300 \\
\hline
\end{tabular}

Sumber : Hasil Analisis Data Primer

Jenis tumbuhan pada tingkat tiang ditemukan 9 jenis dari seluruh plot. Berdasarkan Tabel 2, bahwa nilai kerapatan relatif paling tinggi yaitu jenis Cempaka dan Coklat. Selanjutnya nilai frekuensi relatif paling tinggi yaitu jenis Coklat, sedangkan Cempaka merupakan nilai dominansi relatif yang paling tinggi. Nilai INP tiang yang paling tinggi adalah jenis Cempaka yaitu $74,36 \%$, sehingga jenis tersebut merupakan jenis tiang yang dominan pada kawasan sempadan Embung Bual. Selanjutnya, INP jenis dominan berikutnya yaitu jenis Coklat $(73,58 \%)$. Sementara, jenis yang paling tidak dominan yaitu jenis Kopi $(11,56 \%)$.

Tabel 2. Indeks Nilai Penting Tiang

Table 2. The Importance Value of Poles

\begin{tabular}{lllcccc}
\hline No & \multicolumn{1}{c}{ Jenis Pohon } & \multicolumn{1}{c}{ Nama IImiah } & $\begin{array}{c}\text { Kerapatan } \\
\text { Relatif (KR) } \\
(\%)\end{array}$ & $\begin{array}{c}\text { Frekuensi } \\
\text { Relatif (FR) } \\
(\%)\end{array}$ & $\begin{array}{c}\text { Dominansi } \\
\text { Relatif (DR) } \\
(\%)\end{array}$ & INP (\%) \\
\hline 1 & Cempaka & Magmolia champaca & 24,14 & 23,56 & 26,67 & 74,36 \\
2 & Coklat & Theobroma cacao & 24,14 & 29,45 & 20,00 & 73,58 \\
3 & Mahoni & Swietenia mahagoni & 3,45 & 5,89 & 4,44 & 13,78 \\
4 & Kepundung & Baccaurea racemosa & 13,79 & 5,89 & 13,33 & 33,02 \\
5 & Beringin & Picus benjamina & 13,79 & 5,89 & 17,78 & 37,46 \\
6 & Kumbi/Jembirit & Tabernaemontana sphaerocarpa & 3,45 & 5,89 & 2,22 & 11,56 \\
7 & Awar-awar/Lembokek & Picus septica & 10,34 & 11,78 & 8,89 & 31,01 \\
8 & Kopi & Coffea & 3,45 & 5,89 & 2,22 & 11,56 \\
9 & Kulur & Artocarpus communis & 3,45 & 5,89 & 4,44 & 13,78 \\
& & Jumlah & 100 & 100 & 100 & 300 \\
\hline
\end{tabular}

Sumber : Hasil Analisis Data Primer

Tabel 3. Indeks Nilai Penting Sapihan

Table 3. The Importance Value of Saplings

\begin{tabular}{cllccc}
\hline No & \multicolumn{1}{c}{ Jenis Pohon } & \multicolumn{1}{c}{ Nama llmiah } & $\begin{array}{c}\text { Kerapatan Relatif } \\
\text { (KR) (\%) }\end{array}$ & $\begin{array}{c}\text { Frekuensi Relatif } \\
\text { (FR) (\%) }\end{array}$ & INP (\%) \\
\hline 1 & Kopi & Coffea & 19,05 & 8,70 & 27,75 \\
2 & Kumbi/Jembirit & Tabernaemontana sphaerocarpa & 33,33 & 21,76 & 55,09 \\
3 & Coklat & Theobroma cacao & 2,38 & 8,70 & 11,08 \\
4 & Dadap & Erythrina longipes & 2,38 & 4,35 & 6,73 \\
5 & Dao & Dracontomelon dao & 1,19 & 4,35 & 5,54 \\
6 & Api-api & Avicennia lanata & 23,81 & 21,76 & 45,57 \\
7 & Beringin & Picus benjamina & 1,19 & 4,35 & 5,54 \\
8 & Mahoni & Swietenia mahagoni & 9,52 & 8,70 & 18,23 \\
9 & Saropan & Macaranga tanarius & 1,19 & 4,35 & 5,54 \\
10 & Awar-awar/Lembokek & Picus septica & 3,57 & 4,35 & 7,92 \\
11 & Cempaka & Magmolia champaca & 2,38 & 8,70 & 11,08 \\
& & Jumlah & 100 & 100 & 200 \\
\hline
\end{tabular}

Sumber : Hasil Analisis Data Primer

Pada tingkat hidup sapihan, jenis tumbuhan yang ditemukan 11 jenisPada setiap plot. Berdasarkan hasil analisis vegetasi yang ditunjukkan pada Tabel 3, nilai kerapatan relatif 
paling tinggi yaitu jenis Kumbi, dan nilai frekuensi relatif paling tinggi yaitu jenis Kumbi dan Api-api. Nilai INP sapihan yang paling tinggi yaitu jenis Kumbi yaitu 55,09\%. Berdasarkan nilai tersebut, jenis Kumbi merupakan jenis sapihan yang dominan pada kawasan sempadan Embung Bual, sedangkan yang dominan setelah Kumbi yaitu jenis Api-api (45,57\%). Sementara, jenis yang paling tidak dominan yaitu Beringin dan Saropan (5,54\%).

Jenis yang ditemukan pada tingkat hidup semai terdapat 8 jenis dari keseluruhan plot. Berdasarkan hasil analisis vegetasi yang ditunjukkan pada Tabel 4, nilai kerapatan relatif paling tinggi yaitu jenis Mahonisedangkan nilai frekuensi relatif paling tinggi yaitu Mahoni dan Api-api. Nilai INP pada tingkat semai yang paling tinggi yaitu jenis Mahoni yaitu $88,54 \%$. Berdasarkan nilai tersebut berarti bahwa jenis Mahoni merupakan jenis semai yang dominan pada kawasan sempadan Embung Bual, diikuti Api-api (50,66\%). Jenis yang paling tidak dominan yaitu Pulai dan Coklat $(7,40 \%)$.

Tabel 4. Indeks Nilai Penting Semai

Table 4. The Importance Value of Seedlings

\begin{tabular}{cllccc}
\hline No & Jenis Pohon & \multicolumn{1}{c}{ Nama IImiah } & $\begin{array}{c}\text { Kerapatan Relatif } \\
\text { (KR) (\%) }\end{array}$ & $\begin{array}{c}\text { Frekuensi Relatif } \\
\text { (FR) (\%) }\end{array}$ & INP (\%) \\
\hline 1 & Kopi & Coffea & 3,03 & 11,78 & 14,81 \\
2 & Kumbi/Jembirit & Tabernaemontana sphaerocarpa & 3,03 & 5,89 & 8,92 \\
3 & Mahoni & Swietenia mahagoni & 59,09 & 29,45 & 88,54 \\
4 & Api-api & Avicennia lanata & 21,21 & 29,45 & 50,66 \\
5 & Pulai & Alstonia scholaris & 1,52 & 5,89 & 7,40 \\
6 & Coklat & Theobroma cacao & 1,52 & 5,89 & 7,40 \\
7 & Terep & Picus elastica & 4,55 & 5,89 & 10,43 \\
8 & Nyamplung & Calophyllum inophyllum & 6,06 & 5,89 & 11,95 \\
& & Jumlah & 100 & & 100 \\
\hline
\end{tabular}

Sumber : Hasil Analisis Data Primer

Berdasarkan hasil INP pada keseluruhan fase hidup pohon terdapat perbedaan jenis yang mendominasi pada setiap fase hidup (Tabel 5). Pada fase semai dan pohon didominasi oleh jenis Mahoni yang dapat mengindikasikan bahwa indukan jenis Mahoni yang dominan menghasilkan anakan-anakan semai Mahoni yang dominan juga. Akan tetapi, pada fase sapihan dan tiang jenis tersebut tidak mendominasi. Oleh sebab itu, hal tersebut dapat menjadi indikasi bahwa terdapat gangguan pada pertumbuhan semai menjadi sapihan dan tiang yang menyebabkan penurunan jumlah dan sebarannya.

Tabel 5. Jenis Dominan pada Setiap Fase Hidup Pohon Table 5.The Dominant Species in Each Phase of a Tree Life

\begin{tabular}{cccc}
\hline No. & Fase Hidup & Jenis Dominan & INP $(\%)$ \\
\hline 1 & Semai & Mahoni & 88,54 \\
2 & Sapihan & Kumbi & 55,09 \\
3 & Tiang & Cempaka & 74,36 \\
4 & Pohon & Mahoni & 60,21 \\
\hline
\end{tabular}

Sumber : Hasil Analisis Data Primer

Indeks keanekaragaman menunjukkan tingkat keberagaman jenis dalam suatu komunitas tumbuhan. Keanekaragaman jenis dapat digunakan untuk menilai stabilitas komunitas (Indriyanto, 2006). Keanekaragaman dapat dipengaruhi oleh beberapa faktor seperti kemampuan adaptasi setiap jenis, kompetisi dalam ekosistem, ketersediaan hara dan air, faktor klimatis dan lain sebagainya (Binsasi, Sancayaningsih, \& Murti, 2017). 
Tabel 6. Analisis Indeks Keanekaragaman Kawasan Sempadan Embung Bual Table 6. The Diversity Index Analysis in the Embung Bual Border Area

\begin{tabular}{|c|c|c|c|c|c|c|c|}
\hline No & Jenis & Jumlah individu (ni) & ni-1 & $\mathrm{ni} / \mathrm{n}$ & In ni/n & $\mathrm{ni} / \mathrm{n} \ln \mathrm{ni} / \mathrm{n}$ & ni(ni-1) \\
\hline 1 & Nyamplung & 5 & 4 & 0,0213 & $-3,8501$ & $-0,0819$ & 20 \\
\hline 2 & Coklat & 12 & 11 & 0,0511 & $-2,9747$ & $-0,1519$ & 132 \\
\hline 3 & Nangka & 9 & 8 & 0,0383 & $-3,2624$ & $-0,1249$ & 72 \\
\hline 4 & Mahoni & 61 & 60 & 0,2596 & $-1,3487$ & $-0,3501$ & 3660 \\
\hline 5 & Bunai & 2 & 1 & 0,0085 & $-4,7664$ & $-0,0406$ & 2 \\
\hline 6 & Ara & 3 & 2 & 0,0128 & $-4,3610$ & $-0,0557$ & 6 \\
\hline 7 & Cempaka & 19 & 18 & 0,0809 & $-2,5151$ & $-0,2034$ & 342 \\
\hline 8 & Awar-awar/Lembokek & 9 & 8 & 0,0383 & $-3,2624$ & $-0,1249$ & 72 \\
\hline 9 & Kumbi/Jembirit & 32 & 31 & 0,1362 & $-1,9938$ & $-0,2715$ & 992 \\
\hline 10 & Kepundeng & 3 & 2 & 0,0128 & $-4,3610$ & $-0,0557$ & 6 \\
\hline 11 & Pulai & 2 & 1 & 0,0085 & $-4,7664$ & $-0,0406$ & 2 \\
\hline 12 & Sonokeling & 6 & 5 & 0,0255 & $-3,6678$ & $-0,0936$ & 30 \\
\hline 13 & Sengon & 1 & 0 & 0,0043 & $-5,4596$ & $-0,0232$ & 0 \\
\hline 14 & Terep & 4 & 3 & 0,0170 & $-4,0733$ & $-0,0693$ & 12 \\
\hline 15 & Kepundung & 4 & 3 & 0,0170 & $-4,0733$ & $-0,0693$ & 12 \\
\hline 16 & Beringin & 5 & 4 & 0,0213 & $-3,8501$ & $-0,0819$ & 20 \\
\hline 17 & Kopi & 19 & 18 & 0,0809 & $-2,5151$ & $-0,2034$ & 342 \\
\hline 18 & Kulur & 1 & 0 & 0,0043 & $-5,4596$ & $-0,0232$ & 0 \\
\hline 19 & Dadap & 2 & 1 & 0,0085 & $-4,7664$ & $-0,0406$ & 2 \\
\hline 20 & Dao & 1 & 0 & 0,0043 & $-5,4596$ & $-0,0232$ & 0 \\
\hline 21 & Api-api & 34 & 33 & 0,1447 & $-1,9332$ & $-0,2797$ & 1122 \\
\hline 22 & Saropan & 1 & 0 & 0,0043 & $-5,4596$ & $-0,0232$ & 0 \\
\hline & Jumlah & 235 & 213 & 1 & $-84,18$ & $-2,4319$ & 6846 \\
\hline \multicolumn{3}{|c|}{ Nilai Indeks Keanekaragaman } & \multicolumn{5}{|c|}{ Kategori } \\
\hline \multirow[t]{3}{*}{1} & Simpson & & & & & & \\
\hline & $\Lambda$ & 0,1368 & & & & & \\
\hline & ID & 0,8632 & \multicolumn{5}{|c|}{ Tinggi } \\
\hline 2 & Shannon & 2,4319 & \multicolumn{5}{|c|}{ Tinggi } \\
\hline
\end{tabular}

Sumber : Hasil Analisis Data Primer

Hasil penelitian pada Tabel 6 menunjukkan bahwa tingkat keanekaragaman dianalisis. Jumlah keseluruhan jenis dalam seluruh petak ukur yaitu 22 jenis yang terdiri dari tingkatan hidup semai, sapihan, tiang dan pohon. Berdasarkan hasil indeks keanekaragaman Simpson, komunitas tumbuhan di kawasan sempadan Embung Bual memiliki nilai 0,86. Nilai indeks tersebut termasuk ke dalam kategori tingkat keanekaragaman tinggi. Sementara itu, indeks keanekaragaman Shannon pada komunitas tumbuhan di kawasan sempadan Embung Bual memiliki nilai 2,43, termasuk kategori tingkat keanekaragaman tinggi juga.

Tingkat keanekaragaman yang tinggi menunjukkan bahwa jenis penyusunnya banyak sehingga menciptakan banyak strata vertikal maupun horizontal dalam komunitas tumbuhan. Keberadaan banyak strata vertikal yang ditunjukkan dari keberagaman tinggi pohon dari semai hingga pohon. Hal ini karena dalam menciptakan strata vertikal pada sistem perakaran menyebabkan penyerapan hara dan air pada berbagai lapisan menjadi lebih baik. Selain itu, strata vertikal perakaran mampu memperbaiki struktur dan tekstur tanah pada seluruh strata tanah, sehingga penyerapan air hujan yang jatuh melalui proses infiltrasi menjadi lebih terkendali. Keadaan tersebut menyebabkan air tanah yang akan mengalir ke dalam badan Embung Bual menjadi lestari. 
Strata tinggi pohon yang diciptakan dari keberagaman jenis penyusun komunitas juga mampu meredam energi kinetik air hujan yang jatuh ke permukaan tanah (Naharuddin, 2017)untuk mengerosi tanah, sehingga tanah terlindung dari erosi percik. Selain itu, keberadaan vegetasi di strata bawah mampu menghambat kecepatan aliran permukaan, Oleh sebab itu, vegetasi tersebut mampu meredam erosi di permukaan tanah, sehingga kualitas air tetap terjaga dari suspensi tanah saat terjadi hujan. Hal ini sesuai dengan pernyataan Junardi, Rafdinal, \& Linda, (2018) bahwa keberadaan vegetasi di sempadan mampu mengurangi erosi dan mengurangi sedimen yang masuk ke badan air.

Keberadaan keragaman jenis penyusun dalam kawasan sempadan Embung Bual akan menghasilkan keberagaman seresah daun. Hal tersebut akan memberi manfaat bagi mikroorganisme tanah dalam ketersediaan pakan.Oleh sebab itu, kelangsungan siklus hara di dalamnya juga dapat tetap terjaga. Dengan demikian, tingkat keanekaragaman yang tinggi di kawasan sempadan Embung Bual menunjukkan semakin stabil peranannya dalam menjaga kelestarian kuantitas dan kualitas air Embung Bual.

\section{KESIMPULAN}

Berdasarkan hasil penelitian, kawasan sempadan Embung Bual didominasi oleh jenis Mahoni pada tingkat hidup pohon dengan nilai INP 60,21\%, pada tingkat hidup tiang didominasi oleh jenis Cempaka dengan nilai INP 74,36\%, pada tingkat sapihan didominasi oleh jenis Kumbi dengan nilai INP 55,09\% serta pada tingkat hidup semai didominasi oleh jenis Mahoni dengan nilai INP 88,54\%. Kawasan sempadan Embung Bual memiliki komposisi 22 jenis/spesies dan memiliki indeks keanekaragaman Simpson dengan nilai 0,86 yang termasuk ke dalam kategori tinggi, serta memiliki indeks keanekaragaman Shannon dengan nilai 2,43 yang termasuk ke dalam kategori tinggi.

\section{DAFTAR PUSTAKA}

Asdak, Chay. (2010). Hidrologi dan Pengelolaan Daerah Aliran Sungai. Yogyakarta : Gadjah Mada University Press.

Agustina, L., \& Arisoesilaningsih, E. (2013). Variasi Profil Vegetasi Pohon Riparian di Sekitar Mata air dan Saluran Irigasi Tersier di Kabupaten Malang. Jurnal Biotropika, 1(3), 1-5.

Azizah, P. N. (2017). Analisis Vegetasi di Kawasan Sekitar Mata Air Ngembel, Kecamatan Pajangan, Kabupaten Bantul. Jurnal Riset Daerah, XVI(1), 2685-2702.

Basrowi, M., Hendra, M., \& Hariani, N. (2018). Komposisi dan Struktur Pohon Riparian di Sungai Kahala Kabupaten Kutai Kartanegara. Jurnal Pro-Life, 5(3), 637-649.

Binsasi, R., Sancayaningsih, R. P., \& Murti, S. H. (2017). Analisis Ekologis Vegetasi Pohon di Daerah Tangkapan Air (DTA) Mata Air Geger Kabupaten Bantul Yogyakarta. SAINTEKBU : Jurnal Sains Dan Teknologi, 9(2), 57-66.

Junardi, I. T., Rafdinal, \& Linda, R. (2018). Komposisi Dan Struktur Vegetasi Riparian Di Kawasan Taman Wisata Gunung Poteng Singkawang Kalimantan Barat. Jurnal Protobiont, 7(3), 118-126.

Naharuddin. (2017). Komposisi dan Struktur Vegetasi dalam Potensinya sebagai Parameter Hidrologi dan Erosi. Jurnal Hutan Tropis, 5(2), 6-12.

Yulistyarini, T. (2011). Keragaman Vegetasi dan Pengaruhnya terhadap Laju Infiltrasi di Daerah Resapan Mata Air Seruk, Desa Pesanggrahan - Batu. Jurnal Penelitian Hayati, $5 F($ June), 39-43.

Indriyanto. 2006. Ekologi Hutan. Jakarta : Bumi Aksara.

[Pemerintah RI] Pemerintah Republik Indonesia. (1990). Keputusan Presiden Nomor 32 Tahun 1990 tentang Pengelolaan Kawasan Lindung. 